\title{
Impact of Macro Shocks on Sovereign Default Probabilities
}

\author{
Marco S. Matsumura
}

March 2007

\author{
Department of Macroeconomic Studies. \\ Instituto de Pesquisa Economica Aplicada - Rio de Janeiro. \\ PhD candidate, Instituto Nacional de Matemática Pura e Aplicada. \\ Email: marcom@ipea.gov.br. \\ Address: Av. Presidente Ant ônio Carlos, 51 - 1715. \\ 20020-010, Rio de Janeiro, RJ, Brasil \\ Phone: 552135158533
}

Resumo. Usamos modelos de macro finanças para estudar a interação entre variáveis macro e a curva de juros soberanos do Brasil usando dados diários, de modo a aferir probabilidades de default implícitos do modelo estimado e que impacto choques macro teriam nessas probabilidades. Uma estratégia de identificação de modelos com fatores latentes e observáveis baseado na abordagem de Dai-Singleton é proposto de modo a estimar nossos modelos. Entre as varáveis testadas para a nossa amostra e horizonte, VIX é o fator macro mais importante afetando títulos de curto prazo e probabilidades de default, enquanto a taxa curta americana é o fator mais importante a afetar probabilidades de default de longo prazo.

Abstract. We use macro finance models to study the interaction between macro variables and the Brazilian sovereign yield curve using daily data, in order to assess default probabilities implied from the estimated model and what impact macro shocks would have on those probabilities. An identification strategy for models with latent and observable factors based on Dai-Singleton approach is proposed in order to estimate our models. Among the tested variables for our sample and horizon, VIX is the most important macro factor affecting short term bonds and default probabilities, while the FED FUND short rate is the most important factor affecting the long term default probabilities.

JEL Classifications: C13, E44, G12

Área 7 - Microeconomia, Métodos Quantitativos e Finanças 


\section{Introduction}

Credit risk is an important component of the yield curve of emerging countries. It is linked to some payment obligation and the possible failure of the obligor to honour it, thus affecting the required yield rate a government will face in order to finance itself. This measure will also be of great importance for emerging market firms, since the foreign financing will typically contain the country risk. Firm borrowing rates are usually higher than sovereign rates. Hence, we are led to ask the following questions: What are the factors most affecting the sovereign yield rates? Which variables causes greater impact on default probabilities? We present an empirical investigation using affine term structure models with macro factors and default motivated by such questions.

There are two main lines of credit risk models, the structural and the reduced. In all models, the price of the defaultable bond will depend on the probability of default and on the expected recovery rate upon default. Giesecke (2004) provides a short introductory survey. Black and Scholes (1973) and Merton (1974) initiated the field by proposing the first structural models using option theory. Black and Cox (1976) introduced the basic structural model in which default occurs at the first time the process of the firm's assets crosses a given a default barrier. Many articles were built extending Black and Cox model. More recently, second generation models were introduced by Leland (1994) and Leland and Toft (1996) in which the firm's incentive structure is modelled to determine the default barrier endogenously, obtaining as a result its optimal capital structure. Default occurs when the structure of incentives suggests that it is optimal to the issuer to default or when the payment is impossible. This happens at the time the value of the shares falls to zero.

However, the cited articles treat the corporate credit risk case. The sovereign credit risk differs markedly from the corporate. Some possible reasons for this, taken form Duffie et al (2003), are listed below:

- A sovereign debt investor may not have recourse to a bankruptcy code at the default event.

- Sovereign default can be a political decision. There exists a trade-off between the costs of making the payments and the costs of reputation, of having the assets abroad seized or of having access to international commerce impeded.

- The same bond can be renegotiated many times. Some contracts have cross-default or collective action clauses. Assets in the country cannot be used as a collateral.

- The government can opt for defaulting on internal or external debt.

- Also, one must take into account the role played by key variables such as exchange rates, fiscal dynamics, reserves in strong currency, level of exports and imports, GDP, inflation and many other macro variables.

Therefore, constructing a structural model for the case of a country is a more delicate question. It is not obvious how to model the incentive structure of a government and its optimal default decision, or what "assets" could be seized upon default. Moreover, post-default negotiation rounds regarding the recovery rate can be very complex and uncertain.

Not surprisingly, then, it is difficult to find structural model papers in the sovereign context. Exceptions are Moreira and Rocha (2005) and Ghezzi and Xu (2002). We opt for using reduced models, where the time of default is not directly modelled (see Schönbucher, 2003). It is a totally inaccessible stopping time which is triggered by the first jump of a given exogenous process with default intensity $\lambda$. A totally inaccessible stopping time is defined in the following. A predictable stopping time $\tau$ is one for which there exists a sequence of announcing stopping times $\tau_{1} \leq \tau_{2} \leq \ldots$ such that $\tau_{n}<\tau$ and $\lim \tau_{n}=\tau$ for all $\omega \in \Omega$ with $\{\tau(\omega)>0\}$. In the structural models, if the evolution of the assets follows a Brownian diffusion, then default time is a predictable stopping time. 
A stopping time is totally inaccessible if no predictable stopping time $\tau^{\prime}$ can give any information about $\tau: \mathbb{P}\left[\tau=\tau^{\prime}<\infty\right]=0$. Thus, in the case of the reduced model, the default always comes as a "surprise". This characteristic adds more realism to the modelling. Duffie et al (2003) shows that the MinFins, Russian sovereign bonds, had a price drop of around $80 \%$ in the days immediately following the announcement of the default of the Russian domestic bond GKO in 1998.

Lando (1998) and Duffie and Singleton (1999) developed versions of reduced models in which the default risk appears as an additional instantaneous spread in the pricing equation. The spread can be modelled using additional state factors. In particular, it can be incorporated in the affine model of Duffie and Kan (1996), a largely used model offering a good compromise between flexibility and numerical tractability.

Duffie et al (2003) analyzes the case of the Russian bonds extending the reduced model to include the possibility of multiple defaults (or multiple "credit events", such as restructuring, renegotiation or change of regime). After estimating the model for the risk free reference curve on a first stage and then for defaultable Russian sovereign bonds on a second, they use model implied spreads to examine, for instance, what are the determinants of the spreads, what is the degree of integration between different Russian bonds and what is the correlation between the spreads and the macroeconomic series. They estimated the model in two steps: first the parameters relative to the FED yield curve, then those of the Russian yield curve. Another paper applying reduced model to emerging markets is Pagès (2001).

Duffie et al (2003) and Pagès (2001) only use latent variables. Since macro factors are not explicitly inserted as state variables, they cannot directly affect the latent factors. Also, the impact of changes of bond yields in macro factors cannot be measured within the model.

Ang and Piazzesi (2003) were the first to estimate a term structure model with macro factors alongside latent factors in a discrete time affine model. They incorporate different Taylor rules into the short rate equation used in no arbitrage pricing. In their model, the macro factors affect the entire yield curve. However, the interest rates do not affect the macro factors, which means the monetary policy is ineffective. They estimate in 2 steps: first the macro dynamics and then the latent dynamics conditional on the macro factors. Ang et al (2005) estimate another specification without this drawback using Monte Carlo Markov Chain. A Macro Finance literature has quickly emerged since their work (see Diebold et al, 2005).

Amato and Luisi (2005) use a three-step procedure in a model with macro factors and default risk that addresses the corporate case. First the reference curve, then the macro parameters, and finally the spreads are estimated in a conditional way. However, this has again the restrictive condition that the macro factors are not affected by the yield curve, and the conditioning in multiple steps may lead to sub-optimal solutions.

Our model incorporates the advances brought by the above lines of research to study the impact of macro factors on a defaultable term structure. We provide the comparison among many trial models in the search for the macro factors that influence credit spreads and default probabilities the most. Also, using Ang and Piazzesi's approach, we can use impulse response and variance decomposition techniques to analyze the direct influence of observable macro factors on prices and default probabilities. In pure latent models, the unobservable factors are abstractions that can, at best, be interpreted as geometric factors summarizing the yield curve movements, as seen in Litterman and Scheinkman (1991).

However, before estimating the parameters, one must choose an identification strategy. Not all parameters of the multifactor affine model can be estimated, since there are transformations of the parameter space preserving the likelihood. The specification in Ang et al (2005) is sub-identified, and its parameters can be arbitrarily rotated, while other articles such as Dai and Philippon (2003) propose over-identified specifications. We propose an identification based on Dai and Singleton (2000) that exactly identifies the model. It is also used in Matsumura and Moreira (2006), which addresses the Brazilian domestic market. Another article discussing identification of models with observable and latent factors is Pericoli and Taboga (2006). They propose an exact identification, but it is required 
that the mean reverting matrix of the process driving the state factors, $\Phi$, have real and distinct eigenvalues.

We choose to use continuous-time modelling with high frequency Brazilian and US data because of the limitations of the available size of historical series. When using Brazilian data, one must take into account that frequent changes of regime have occurred until recently, such as change from hyperinflation to a stable economy (Real Plan, July 1994), change from fixed to floating exchange rate in a currency crisis in January 1999, and change of monetary policy to inflation target in July 1999. Thus, our sample starts in 1999, and goes up to 2005.

Our main model contain 5 state variables, one latent for the FED, one for an external macro factor, one for an internal macro factor, and two latent for the Brazilian sovereign yield curve. Macro variables tested are: 1) FED short rate, FED long rate, FED slope, VIX index of implied volatility of options on the Standard \& Poor index, exchange rate, Brazilian stock exchange Bovespa index, Brazilian future exchange interest rate swaps (short-term, long term, slope of the term).

Therefore, our objectives include: 1) analyzing the determinants of the term structure of the Brazilian sovereign interest rates; 2) measuring the forecasting performance of the models; 3) calculating default probabilities and measure the impact of macro shocks on them; 4) proposing an identification for affine models with macro factors.

We report that: 1) VIX and FED strongly affects the default probabilities in the short term and in the long term, respectively. 2) VIX has strong effect on Brazilian sovereign yields, more than any investigated domestic macro indicator. 3) Since the FED short rate affects more the default probabilities than the Brazilian domestic short rate, US monetary policy may cause more impact on the term structure of default probabilities than Brazilian monetary policy.

\section{Model}

Fix the probability space $(\Omega, \mathbb{F}, P)$ and assume no arbitrage. The price at time $t$ of a zero coupon bond paying 1 at the maturity date $t+\tau$ is $P(t, \tau)=E^{\mathbb{Q}}\left[\exp \left(-\int_{t}^{t+\tau} r_{t} d t\right) \mid \mathbb{F}_{t}\right]$. The conditional expectation is taken under the equivalent martingale measure $\mathbb{Q}, t+\tau$ is the maturity date, $r_{t}$ is the stochastic instantaneous rate and $\mathbb{F}_{t}$ is the filtration at time $t$.

The state of the economy is given by $X_{t} \in \mathbb{R}^{d}$ and follows a Gaussian process with mean reversion. Let $r_{t}=\delta_{0}+\delta_{1} \cdot X_{t}$, and under the objective $\mathbb{P}$-measure, $d X_{t}=K\left(\xi-X_{t}\right) d t+\Sigma d w_{t}$. The $d \times d$ and $d \times 1$ parameters $K$ and $\theta$ represent the mean reversion coefficient and the long term instantaneous rate, and $\Sigma \Sigma^{\top}$ is the instantaneous variance-covariance matrix of the standard Brownian motion $w_{t}$.

We let the time-varying risk premium be $\lambda_{t}=\lambda_{0}+\lambda_{1} \cdot X_{t}$. Under the martingale measure $\mathbb{Q}$, using Girsanov, we have $d X_{t}=K^{\star}\left(\xi^{\star}-X_{t}\right) d t+\Sigma d w_{t}^{\star}, d w_{t}^{\star}=d w_{t}+\lambda_{t} d t$, where $K^{\star}=K+\Sigma \lambda_{1}, \xi^{\star}=$ $K^{\star-1}\left(K \xi-\Sigma \lambda_{0}\right)$.Using multifactor Feynman-Kac, we have: let $E^{\mathbb{Q}}\left[\exp \left(-\int_{t}^{t+\tau} r\left(X_{u}\right) d u\right) \mid \mathbb{F}_{t}\right]=$ $v\left(X_{t}, t, \tau\right)$, then $v(x, t, \tau)$ must satisfy the following PDE:

$$
\mathbb{D} v(x, t, \tau)-r(x) v(x, t, \tau)=0, v(x, t, 0)=1,
$$

where the operator $\mathbb{D}$ is given by $\mathbb{D} v(x, t, \tau):=v_{t}(x, t, \tau)+v_{x}(x, t, \tau) \cdot K^{\star}\left(\xi^{\star}-x\right)+\frac{1}{2} \operatorname{tr}\left[\Sigma \Sigma^{\top} v_{x x}(x, t, v)\right]$. The solution is exponential affine on the state variables, $v(t, \tau, x)=e^{\alpha(\tau)+\beta(\tau) \cdot x}$, where $\beta \prime(\tau)=$ $-\delta_{1}-K^{\star \top} \beta(\tau)$ and $\alpha \prime(\tau)=-\delta_{0}+\xi^{\star \top} K^{\star \top} \beta(\tau)+\frac{1}{2} \beta(\tau)^{\top} \Sigma \Sigma \mathrm{T} \beta(\tau)$. An explicit solution of this system of ODE's exists only in some special cases, such as diagonal $K$, but Runge-Kutta numerical integration provides accurate approximations.

Hence, the yield is given by an affine function of the state variables, $Y(t, \tau)=A(\tau)+B(\tau) \cdot X_{t}$, where $A(\tau)=-\frac{\alpha(\tau)}{\tau}$ and $B(\tau)=-\frac{\beta(\tau)}{\tau}$. If we stack the equations for the $K$ yield maturities, then $Y_{t}=A+B X_{t}$, where $Y_{t}=\left(Y\left(t, \tau_{1}\right), \ldots, Y\left(t, \tau_{K}\right)\right)^{\top}$. The factor loadings $A$ and $B$ will depend on the set of parameters $\Psi=\left(\delta_{0}, \delta_{1}, K, \theta, \lambda_{0}, \lambda_{1}, \Sigma\right)$. 
The likelihood is the density function of the sequence of observed yields $\left(Y_{t_{1}}, \ldots, Y_{t_{n}}\right)$, which is found integrating the transition density of $X_{t_{i}} \mid X_{t_{i-1}}$ :

$$
X_{t_{i} \mid t_{i-1}}=\left(1-e^{-K\left(t_{i}-t_{i-1}\right)}\right) X_{t_{i-1}}+e^{-K\left(t_{i}-t_{i-1}\right)} \theta+\int_{t_{i-1}}^{t_{i}} e^{-K\left(t_{i}-u\right)} \Sigma d w_{u} .
$$

Using Ito's isometry formula, it follows that the stochastic integral term above is Gaussian with mean zero and variance

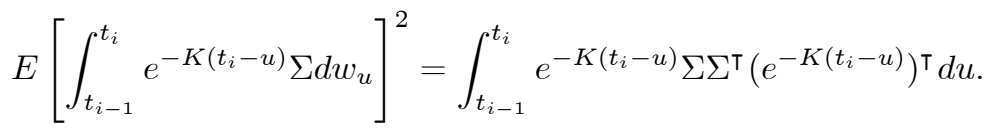

This means that $X_{t_{i} \mid t_{i-1}} \sim N\left(\mu_{i}, \sigma_{i}^{2}\right)$, where $\mu_{i}=\left(1-e^{-K\left(t_{i}-t_{i-1}\right)}\right) X_{t_{i-1}}+e^{-K\left(t_{i}-t_{i-1}\right)} \theta$ and $\sigma_{i}^{2}=$ $\int_{t_{i-1}}^{t_{i}} e^{-K\left(t_{i}-u\right)} \Sigma \Sigma^{\top}\left(e^{-K\left(t_{i}-u\right)}\right)^{\top} d u$.

Since $d t=t_{i}-t_{i-1}$ is small, since daily frequency is used, a very good approximation to the integral

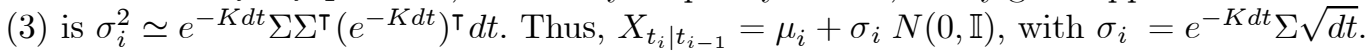

Now suppose the vectors $X_{t}$ and $Y_{t}$ have the same dimension, that is, the number of yield maturities equals the number of state variables. Then, we can invert a linear equation and find $X_{t}$ as a function $h$ of $Y_{t}: X_{t}=B^{-1}\left(Y_{t}-A\right)=h\left(Y_{t}\right)$. Using change of variables, it follows that $\log f_{Y}\left(Y_{t_{1}}, \ldots, Y_{t_{n}} ; \Psi\right)=$ $\left.\log f_{X}\left(X_{t_{1}}, \ldots, X_{t_{n}}\right) ; \Psi\right)+\log |\operatorname{det} \nabla h|^{n}$.

The procedure above restricts the number of yield maturities that can be used, because of the inversion used to obtain the model implied state vector. If we want to use more data available, that becomes a problem, since the additional yields make the model singular. One solution is to follow Chen and Scott (1993), and add measurement errors to some yields. Let $d$ and $K$ be the number of state variables and of maturities. We select $d$ maturities out of $K$ to be priced without error. Let $Y_{t}^{1}$ represent the set of those yields at a given time. The other yields are denoted by $Y_{t}^{2}$, and they will have independent normal measurement errors $u(t, \tau) \sim N\left(0, \sigma_{u}^{2}(\tau)\right)$.

\subsection{Adding Default and Macro Factors}

An important component in the term structure of emerging countries is the spread due to the possibility of default. We use Duffie and Singleton's version of the reduced model. The price $P^{D}$ of a defaultable bond is

$$
P^{D}(t, \tau)=E^{\mathbb{Q}}\left[1_{[T>t+\tau]} \exp \left(-\int_{t}^{t+\tau} r_{t} d t\right)+W_{T} 1_{[T \leq t+\tau]} \exp \left(-\int_{t}^{T} r_{t} d t\right) \mid \mathbb{F}_{t}\right] .
$$

The first part is what the bond owner receives if the maturity time comes before the default time $T$, a stopping time. In case of default, the investor receives the random variable $W_{T}$ at the default time. If $T$ is doubly stochastic with intensity $\lambda$, if the recovery upon default is given by $W_{T}=\left(1-l_{T}\right) P_{T}$, where $l(t)$ is the loss rate, and if other technical conditions are satisfied, Lando (1998) and Duffie and Singleton (1999) prove that

$$
P^{D}(t, \tau)=E^{\mathbb{Q}}\left[\exp \left(-\int_{t}^{t+\tau}\left(r_{t}+s_{t}\right) d t\right) \mid \mathbb{F}_{t}\right]
$$

where $s_{t}=l_{t} \lambda_{t}$ is the spread due to the possibility of default.

We briefly explain the concept of doubly stochastic stopping time (see Schönbucher, 2003, Duffie, 2001). Define $N(t)=1_{[T \leq t]}$ the associated counting process. It can be shown that $N(t)$ is a submartingale. Applying the Doob-Meyer theorem, we know there exists a predictable, nondecreasing 
process $A(t)$ called the compensator of $N(t)$. One property of the compensator is to give information about the probabilities of the jump time. The expected marginal increments of the compensator $d A(t)$ is equal to the probability of the default occurring in the next increment of time: $E\left[A(t+\Delta t)-A(t) \mid \mathbb{F}_{t}\right]=P\left[N(t+\Delta t)-N(t)=1 \mid \mathbb{F}_{t}\right]$. An intensity process $\lambda_{t}$ for $N(t)$ exists if it is progressively measurable and non negative, and if $A(t)=\int_{0}^{t} \lambda(s) d s$.It turns out, under regularity conditions, that

$$
\lambda(t)=\lim _{\Delta t \rightarrow 0} \frac{1}{\Delta t} P[T \leq t+\Delta t \mid T>t] .
$$

So, $\lambda(t)$ represents the evolution of the instantaneous probability of defaulting by $T+t$ if default has not occurred up to $T$.

The instantaneous spread is affine, $s_{t}=\delta_{0}^{s}+\delta_{1}^{s} \cdot X_{t}$, and the state vector $X_{t}$ incorporates state variables relative to the defaultable yields, following a Gaussian process. The discount rate is $R_{t}=r_{t}+s_{t}=\delta_{0}^{r}+\delta_{0}^{s}+\left(\delta_{1}^{r}+\delta_{1}^{s}\right) \cdot X_{t}=R\left(X_{t}\right)$. Set $\lambda_{t}^{s}=\lambda_{0}^{s}+\lambda_{1}^{s} \cdot X_{t}$. The price of the defaultable bond is exponential affine, $P^{D}(t, \tau)=\exp \left(\alpha^{D}(\tau)+\beta^{D}(\tau) \cdot X_{t}\right)$, where $\alpha^{d}$ and $\beta^{d}$ solve $\frac{\beta^{D}(\tau)}{d \tau}=-\left(\delta_{1}^{r}+\delta_{1}^{s}\right)-K^{\star T} \beta^{D}(\tau)$ and $\frac{\alpha^{D}(\tau)}{d \tau}=-\left(\delta_{0}^{r}+\delta_{0}^{s}\right)-K^{\star T} \theta^{\star T} \beta^{D}(\tau)+\frac{1}{2} \beta^{D}(\tau)^{T} \Sigma \Sigma^{T} \beta^{D}(\tau)$. Thus, we have $Y^{D}(t, \tau)=A^{D}(\tau)+B^{D}(\tau) \cdot X(t)$, where $A^{D}(\tau)=-\frac{\alpha^{D}(\tau)}{\tau}, B^{D}(\tau)=-\frac{\beta^{D}(\tau)}{\tau}$, or, piling the equations, $Y_{t}^{D}=A^{D}+B^{D} \cdot X_{t}$.

The likelihood function turns out to be equal to the previous case, except by the increased dimension. Duffie at al (2003) opted to make a 2 step maximization in which the reference curve parameters are estimated first, following the estimation of the yield spread curve parameters conditional on the estimated parameters. They assumed a "triangular" form for the dynamics of the state variables. The American short rate is affected the Russian short rate, but not vice-versa. We use the same idea, observing that a one step procedure could be used (as is explained later), but would increase the computational complexity. The state vector contains the reference and the emerging market state vectors.

The final model is completed adding the macro state factors. Let $X_{t}=\left(M_{t}, \theta_{t}\right)$, where $M_{t}$ are macro variables and $\theta_{t}$ the latent variables. The short rate combines the Taylor Rule and the affine model: $r_{t}=\delta_{0}+\delta_{11} \cdot M_{t}+\delta_{12} \cdot \theta_{t}$, which permits studying the inter-relations between macroeconomic questions, such as monetary policy, and finance problems, such as derivative pricing, while affine tractability is retained. In fact, similar calculations result in $Y(t, \tau)=A(\tau)+B^{M}(\tau) \cdot M_{t}+B^{\theta}(\tau) \cdot \theta_{t}$.

The likelihood is calculated as follows. Adding maturities $Y_{t}^{2}$ with measurement errors $u_{t}$, we have:

$$
\left[\begin{array}{c}
M_{t} \\
Y_{t}^{1} \\
Y_{t}^{2}
\end{array}\right]=\left[\begin{array}{c}
0 \\
A^{1} \\
A^{2}
\end{array}\right]+\left[\begin{array}{ccc}
1 & 0 & 0 \\
B^{M 1} & B^{\theta 1} & 0 \\
B^{M 2} & B^{\theta 2} & 1
\end{array}\right]\left[\begin{array}{c}
M_{t} \\
\theta_{t} \\
u_{t}
\end{array}\right]
$$

Denote by $h$ the function that maps the state vector $\left(X_{t}, u_{t}\right)$ to $\left(X_{t}^{o}, Y_{t}, Y_{t}^{2}\right)$. One obtains $\theta_{t}$ inverting on $Y_{t}^{1}: \theta_{t}=\left(B^{\theta 1}\right)^{-1}\left(Y_{t}^{1}-A^{1}-B^{M 1} \cdot M_{t}\right)$. Then

$$
\begin{gathered}
\left.\log f_{Y}\left(Y_{t_{1}}, \ldots, Y_{t_{n}} ; \Psi\right)=\log f_{X}\left(X_{t_{1}}, \ldots, X_{t_{n}}\right) ; \Psi\right)+\log f_{u}\left(u_{t_{1}, \ldots,} u_{t_{n}}\right)+\log |\operatorname{det} \nabla h|^{n} \\
=-(n-1) \log \left|\operatorname{det} B^{u 1}\right|+\sum_{t=2}^{n} \log f_{X_{t} \mid X_{t-1}}\left(X_{t} ; \Psi\right)+\log f_{u}\left(u_{t}\right) .
\end{gathered}
$$

In a model in which the macro factors are not affected by the yield curve like Ang and Piazzesi (2003), the parameters are also distributed in a triangular form, so that the macro factors can be estimated separately in a first step. Our estimations, like Ang et al (2005), allow macro factors and the yield factors to fully interact. However, we also use a two step estimation in models containing the reference and the emerging curve. We assume that the US yield curve is not affected by the Brazilian yield curve and estimate it in a first step. 
Observe that a credit risk reduced model can substitute the term structure model with macro factors if we look to the US yield curve as macro factors influencing the emerging curve. However, the interpretation of the spread as the instantaneous expected loss given by the Duffie and Singleton (1999) model will be lost, together with the calculation of model implied default probabilities.

Finally, we remark that it is possible to make one-step estimations of the US and the Brazilian yield curve and the macro factors. Since we suppose that the US yield curve parameters are not affected by the Brazilian parameters, the joint probability density of the yield curves and macro factors can be decomposed:

$$
f\left(Y^{U S}, Y^{B R}, M^{U S}, M^{B R} ; \Psi^{U S}, \Psi^{B R}\right)=f\left(Y^{U S}, M^{U S} ; \Psi^{U S}\right) f\left(Y^{B R}, M^{B R} ; \Psi^{B R} \mid Y^{U S}, M^{U S} ; \Psi^{U S}\right) .
$$

Thus, the $\log$ likelihood will be the sum of two functions, one depending on $\Psi^{U S}$ and the other on $\left(\Psi^{U S}, \Psi^{B R}\right)$. However, the maximization becomes much more difficult and we avoided it.

\section{Identification}

The complete set of parameters are distributed as follows. The number of state variables is $d$, of yield maturities is $m$, and of latent variables is $n$.

$$
\begin{aligned}
& \xi^{\top}, \xi^{* \top} \in \mathbb{R}^{d} ; \sigma_{u}^{\top} \in \mathbb{R}^{m-n} ; \Sigma=\left(\begin{array}{cc}
\Sigma_{M M} & \Sigma_{M \theta} \\
\Sigma_{\theta M} & \Sigma_{\theta \theta}
\end{array}\right) \in \mathbb{R}^{d \times d}, \\
& K=\left(\begin{array}{cc}
K_{M M} & K_{M \theta} \\
K_{\theta M} & K_{\theta \theta}
\end{array}\right) ; K^{*}=\left(\begin{array}{cc}
K_{M M}^{*} & K_{M \theta}^{*} \\
K_{\theta M}^{*} & K_{\theta \theta}^{*}
\end{array}\right) \in \mathbb{R}^{d \times d} .
\end{aligned}
$$

The model need to be identified. We extend the canonical identification of Dai and Singleton (2000) for the case with observable factors. It is shown below that if we set $\xi^{\theta}=0, \Sigma_{\theta \theta}=\mathbb{I}$ (the identity matrix), $\Sigma_{M \theta}=0$, and impose that $K_{\theta \theta}, \Sigma_{\theta \theta}$ and $\Sigma_{M M}$ are lower triangular, then the model is exactly identified. We subtract the sample mean from the macro factors, so that $\xi^{M}=0$ and hence $\xi=0$.

It can be shown that Ang et al (2005) is not fully identified, while Dai and Philippon (2004), Hördahl et al (2004) and Amato and Luisi (2005) use over-identifying restrictions that are not motivated by economic reasons. Pericoli and Taboga (2006) also points out the way to achieve an exact identification, but they require that the mean reverting matrix of the state vector process $K$ have real and distinct eigenvalues.

Invariant transformations on the parameter space can arbitrarily change the impulse response functions of the latent factors if the specification is sub-identified. On the other hand, over-identified models produce sub-optimal results and may artificially distort the impulse response functions.

However, when we are interested in models properties with respect to observable factors, the choice of the specification does not matter.

Proposition 1 DS invariant transformations preserve the pricing equation and the impulse response function of the yield function.

Proof. See Appendix.

Proposition 2 DS invariant transformations preserve the likelihood of the affine model with observable factors under Chen-Scott.

Proof. See Appendix. 
We assume that the state factors have a given intertemporal causality ordering in $\Sigma$ as in the VAR literature. The FED rate is always the more exogenous factor, followed by the VIX, the domestic macro factors and the latent factors.

We did impose a slight super identifying restriction because our $K_{\theta \theta}^{*}$ is also lower triangular. Summing up, we have:

$$
\Sigma=\left(\begin{array}{cc}
\Sigma_{M M} & 0 \\
0 & \mathbb{I}
\end{array}\right), \xi=0, \text { and } K_{\theta \theta}, K_{\theta \theta}^{*}, \Sigma_{M M} \text { lower triangular. }
$$

An especial case is obtained when $K_{M \theta}=K_{M \theta}^{*}=0$, which is called macro-to-yield, since the macro factors affect but are not affected by the financial latent factors. Another case is the yield-to-macro, in which $K_{\theta M}=K_{\theta M}^{*}=0$. Here, yield curve affect macro factors but not vice-versa in the transition equation $d X_{t}=K\left(\xi-X_{t}\right) d t+\Sigma d w_{t}$. However, macro factors still affect the yield curve through the short rate equation, $r_{t}=\delta_{0}+\delta_{1} \cdot X_{t}$. The two restricted specifications are called unilateral, while the unrestricted is called bilateral.

We estimated 2 families of increasing difficulty specifications. The first is preliminary, consisting of macro-to-yield models with one macro factor and two latent factors for the Brazilian yield curve; and second is the main one, consisting of bilateral models with two macro factors, one FED and two Brazilian latent factors.

\subsection{IRF, Variance Decomposition and Default Probabilities.}

The continuous-time version of the impulse response functions and variance decomposition are detailed in the appendix. The term structure of default probabilities, which is given by $\operatorname{Pr}(t, \tau)=$ $E^{\mathbb{P}}\left[\exp \left(-\int_{t}^{t+\tau} s_{t} d t\right) \mid \mathbb{F}_{t}\right]$, can be calculated as in the pricing case. It turns out that $\operatorname{Pr}(t, \tau)=$ $\exp \left(\alpha^{\operatorname{Pr}}(\tau)+\beta^{\operatorname{Pr}}(\tau) \cdot X_{t}\right)$, with $\alpha^{\operatorname{Pr}}$ and $\beta^{\operatorname{Pr}}$ given by $\frac{\beta^{\operatorname{Pr}}(\tau)}{d \tau}=-\delta_{1}^{s}-K^{T} \beta^{\operatorname{Pr}}(\tau)$ and $\frac{\alpha^{\operatorname{Pr}}(\tau)}{d \tau}=$ $-\delta_{0}^{s}-K^{T} \theta^{T} \beta^{\operatorname{Pr}}(\tau)+\frac{1}{2} \beta^{\operatorname{Pr}}(\tau)^{T} \Sigma \Sigma^{T} \beta^{\operatorname{Pr}}(\tau)$. Note that the expectation is taken under the objective measure. The log of the probabilities is again an affine function of the state variables, $\log \operatorname{Pr}(t, \tau)=$ $\alpha^{\operatorname{Pr}}(\tau)+\beta^{\operatorname{Pr}}(\tau) \cdot X(t)$.

\section{Estimation}

The parameters are chosen maximizing the log-likelihood given the series of yields and observable factors. Maximum likelihood produces asymptotically consistent, non-biased and normally distributed estimators. Let $L=\log f_{Y}$. When $T \rightarrow \infty$, we have $\hat{\psi} \rightarrow \psi$ a.s., and $T^{\frac{1}{2}}(\hat{\psi}-\psi) \rightarrow N(0, \Omega)$ in distribution, where $\Omega^{-1}=E\left(\frac{\partial L(Y ; \psi)}{\partial \psi} \frac{\partial L(Y ; \psi)^{T}}{\partial \psi}\right)=-E\left(\frac{\partial^{2} L(Y ; \psi)}{\partial \psi^{2}}\right)$ using the information inequality. An estimator for $\Omega^{-1}$ is the empirical Hessian $\hat{\Omega}^{-1}:=-\frac{1}{n} \sum_{t=1}^{n}\left(\frac{\partial^{2} L_{t}(Y ; \hat{\psi})}{\partial \psi^{2}}\right)$, where $L_{t}$ represents the likelihood of the vector with $t$ elements (see Davidson and Mackinnon, 1993). Confidence intervals for the parameter estimations are found using the empirical Hessian and the Central Limit Theorem. If the number of observations $n$ is large enough, then the variance of $\hat{\psi}-\psi$ will be given by the diagonal of $N(0, \Omega / n)$. Alternatively, one could obtain the confidence interval via simulation.

Our estimation strategy consisted in may trial optimizations using Matlab. We begun with the simpler macro-to-yield models with less parameters, choosing different starting vectors in the numerical optimization. Then, the result was used in models with higher dimensions. New trials from random vectors were conducted and compared., and the maximal results were chosen. Although this procedure may be path-dependent, the "curse of dimensionality" does not allow the use of a complete grid of random starting points as would be desirable. 


\subsection{Data}

We use the constant maturity zero-coupon term structure from BM\&F (the Brazilian Futures Exchange) interest rate swaps, the FED constant maturity zero-coupon yield curve, the constant maturity zero-coupon term structure of spreads from Bloomberg, the Chicago Board Options Exchange Volatility Index - VIX -, created from S\&P 500 index options implied volatilities, the BR Real/US Dollar exchange rate and Bovespa index of the Brazilian Stock Exchange most traded firms, and finally the Brazilian Government Debt over GDP.
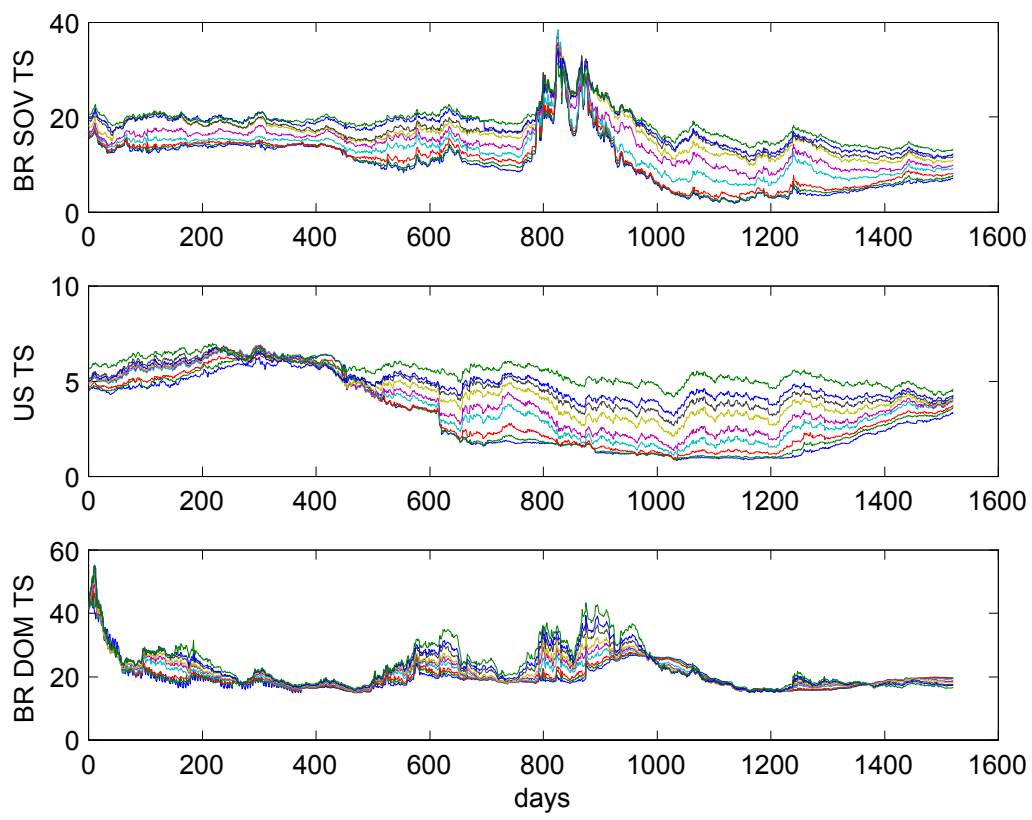

Figure 1:

The sample used for the estimation begins on February $17^{\text {th }} 1999$, and ends on September $15^{\text {th }}$ 2004, comprising 1320 days. More 200 days of available data, finishing on July $21^{\text {st }} 2005$, were separated to test the forecasting performance. The maturities of the FED and sovereign Brazilian yield curve are the same: $\{3 \mathrm{~m}, 6 \mathrm{~m}, 1 \mathrm{y}, 2 \mathrm{y}, 3 \mathrm{y}, 5 \mathrm{y}, 10 \mathrm{y}, 20 \mathrm{y}\}$. We choose $3 \mathrm{~m}$ and the $5 \mathrm{y}$ as the yield maturities priced without without measurement errors in the Chen-Scott inversion. We took the log of the exchange rate and of the Bovespa index, since our model is linear on the state variables. The Debt series have yearly frequency, and was used only in the model with variable premium parameters.

The sample starts one month after the change of regime of the exchange rate from fixed to floating in January of 1999, forced by a devaluation crisis.

\section{Results}

\subsection{Macro-to-yield without default}

We begin presenting and comparing the simplest specification, whose main utility is to select macro factors to use in other models. The trial models have 3 state variables, $X=\left(M, \theta_{1}, \theta_{2}\right)$, one macro 

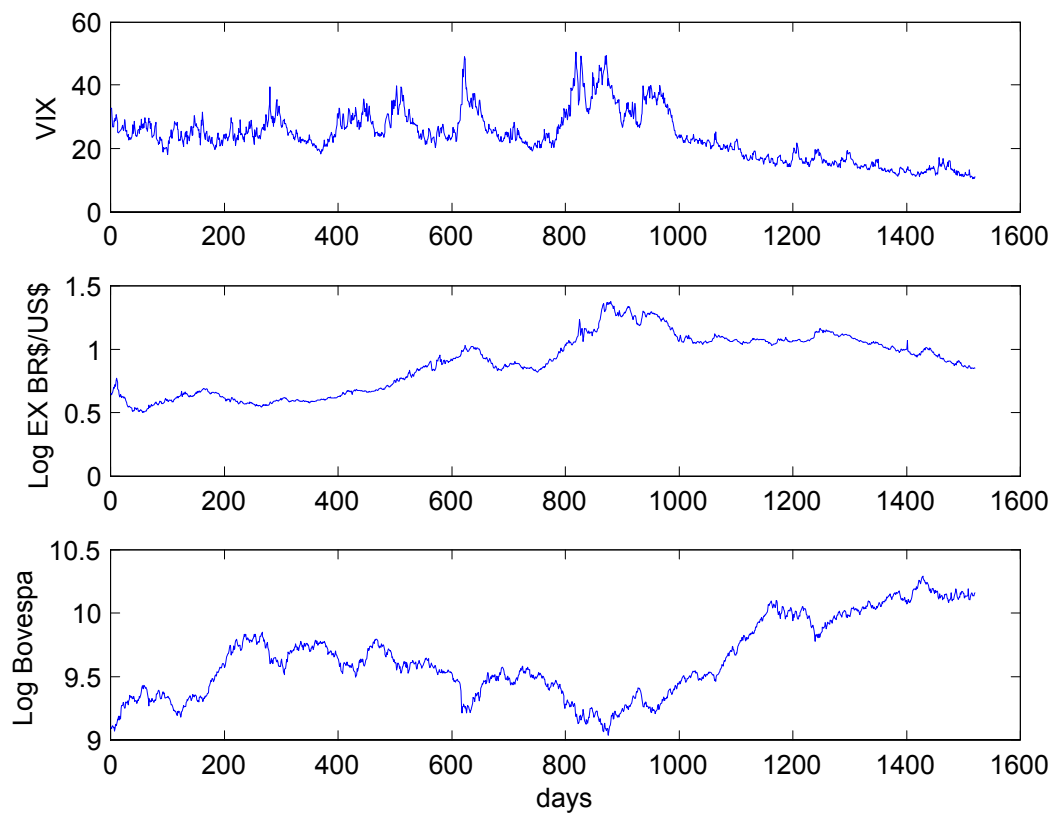

Figure 2:

and two latent, characterized by the macro-to-yield dynamics. The following macro variables are used: 1) VIX, 2) BR Real/US Dollar exchange rate, 3) Bovespa, 4) BM\&F 1-month yield, 5) BM\&F 3-years yield and 6) BM\&F slope = 3y - 1m yields, 7) FED 1-month yield, 8) FED 10-years yield and 9) FED slope $=10 \mathrm{y}-1 \mathrm{~m}$ yields. The Table 1 contain the following information: A) the log-likelihood divided by the number of observations, B) a measure of adherence given by the model in-sample mean squared error divided by the random walk mean squared error, C) the out-of-sample forecasting performance, or Theil-U, D) the correlation between the latent factors and the sovereign level and slope, and E) the mean of the measurement errors in basis points.

The adjustment and Theil-U are given by the standard deviation of a 1-month forecasting error of selected maturities, normalized by the standard deviation of a model that follows a random walk. That is, the in-sample adherence and the Theil-U are given by $\left(\frac{\sum_{t}\left(Y_{t}-\widehat{Y}_{t \mid t-21}\right)^{2}}{\sum_{t}\left(Y_{t}-Y_{t-21}\right)^{2}}\right)^{\frac{1}{2}}$, where sums are in or out-of-sample, respectivelly.

The results of the Macro 1D unilateral models are shown in the table. The in-sample adherence of the specifications are similar, having RMSEs roughly the same size as the RW. The mean of all the measurement errors excluding the exactly priced $3 \mathrm{~m}$ and $5 \mathrm{y}$, is around 80 basis points. In term of likelihood, the specifications using the Fed Fund have higher results. However, no model could actually have any forecasting capacity. The latent factor $\theta_{2}$ is highly correlated to the level in all cases, while $\theta_{1}$ is not highly correlated to the slope for some maturities.

Table 1. Summary of Macro 1D unilateral + BR 2D models. All have 26 parameters. 


\begin{tabular}{c|ccccccccc} 
& VIX & EX & bove & bmf1m & bmf3y & bmfsl & fed1m & fed10y & fedsl \\
\hline \hline LL/T & 44.66 & 44.25 & 44.25 & 44.75 & 44.79 & 44.95 & 47.52 & 47.46 & 47.07 \\
M(In) & 1.14 & 1.04 & 1.10 & 1.03 & 1.03 & 1.09 & 1.04 & 1.03 & 1.06 \\
TU3m & 2.02 & 0.76 & 2.58 & 2.51 & 2.50 & 6.00 & 2.16 & 2.15 & 2.21 \\
TU1y & 1.54 & 1.27 & 2.77 & 2.48 & 2.41 & 4.05 & 2.32 & 2.71 & 2.26 \\
TU5y & 1.37 & 0.96 & 2.03 & 1.33 & 1.31 & 3.98 & 1.27 & 1.75 & 1.05 \\
TU10y & 2.85 & 3.73 & 1.39 & 2.86 & 2.88 & 5.24 & 2.13 & 2.37 & 2.65 \\
c $\left(\theta_{1}, \mathrm{~s}\right)$ & -0.20 & -0.37 & -0.29 & -0.59 & -0.56 & -0.57 & -0.66 & -0.69 & -0.61 \\
$\mathrm{c}\left(\theta_{2}, 1\right)$ & 0.99 & 0.83 & 0.98 & 0.94 & 0.94 & 1.00 & 0.94 & 0.84 & 0.94 \\
$\mathrm{M}\left(\sigma_{u}\right)$ & 72 & 88 & 74 & 82 & 83 & 77 & 82 & 81 & 83
\end{tabular}

Next table measures the proportion the macro factors explain in the variance decompositions for forecast horizons of $\{1 \mathrm{~m}, 9 \mathrm{~m}\}$-ahead of the $\{3 \mathrm{~m}, 3 \mathrm{y}, 20 \mathrm{y}\}$-yields.

Table 2. Variance decomposition of yields. Macro 1D unilateral + BR2D models. Contribution of the macro factor for 1 and 9-month horizons.

\begin{tabular}{|c|c|c|c|c|c|c|c|c|c|c|c|c|c|c|c|c|c|c|}
\hline Resp & \multicolumn{2}{|c|}{ VIX } & \multicolumn{2}{|c|}{ EX } & \multicolumn{2}{|c|}{ Bove } & \multicolumn{2}{|c|}{ bmf1m } & \multicolumn{2}{|c|}{ bmf3y } & \multicolumn{2}{|c|}{ bmfsl } & \multicolumn{2}{|c|}{ fed1m } & \multicolumn{2}{|c|}{ fed10y } & \multicolumn{2}{|c|}{ fedsl } \\
\hline & 1 & 9 & 1 & 9 & 1 & 9 & 1 & 9 & 1 & 9 & 1 & 9 & 1 & 9 & 1 & 9 & 1 & 9 \\
\hline $3 \mathrm{~m}$ & 15 & 31 & 07 & 07 & 01 & 22 & 00 & 00 & 00 & 00 & 16 & 46 & 00 & 00 & 00 & 02 & 00 & 06 \\
\hline $3 y$ & 23 & 46 & 09 & 11 & 00 & 13 & 00 & 00 & 00 & 00 & 23 & 61 & 00 & 00 & 04 & 10 & 00 & 07 \\
\hline $20 y$ & 54 & 69 & 09 & 14 & 06 & 21 & 00 & 00 & 00 & 00 & 50 & 79 & 00 & 00 & 08 & 16 & 00 & 07 \\
\hline
\end{tabular}

Table 2 compares the importance of the different macro variables for the sovereign yield curve. It is the criterion we use to select the variables to be used in the next models, because we are interested in the macro factors most influencing the yield curve. The ordering of the impact is the following: 1) Greater effect: VIX and BM\&F slope; 2) Some effect: exchange rate, 10 years FED yield, FED slope, Bovespa index; 3) Negligible effect: BM\&F 1 month and 3 years yield, FED 1-month yield.

\subsection{Bilateral models}

This subsection present the specifications with one FED latent factor, an internal and an external macro factor, and two Brazilian latent factors. The domestic macro factor has a bilateral interaction with the sovereign Brazilian factors, that is, the macro factors and the sovereign yield curves fully interact.

Table 3. Summary of FED 1D + Macro 2D bilateral + BR 2D. All have 51 parameters.

\begin{tabular}{c|ccccc} 
& vix bmf 3m & vix bmf sl & vix bmf 3y & vix lbov & vix lbov/ex \\
\hline \hline LL/T & 52.90 & 52.52 & 52.91 & 55.81 & 55.57 \\
M(In) & 1.00 & 0.99 & 1.02 & 1.04 & 1.05 \\
TU3m & 2.77 & 2.80 & 3.20 & 3.82 & 3.42 \\
TU1y & 2.29 & 2.35 & 2.56 & 4.45 & 4.04 \\
TU5y & 1.02 & 1.04 & 1.03 & 3.20 & 2.65 \\
TU10y & 2.29 & 2.40 & 2.12 & 1.77 & 1.45 \\
$\mathrm{c}\left(\theta_{1}, \mathrm{~s}\right)$ & -0.08 & -0.48 & -0.04 & -0.86 & -0.86 \\
$\mathrm{c}\left(\theta_{2}, 1\right)$ & 0.92 & 0.93 & 0.93 & 0.96 & 0.96 \\
$\mathrm{M}\left(\sigma_{u}\right)$ & 61 & 62 & 61 & 67 & 68
\end{tabular}

Table 3 is a summary of the main models. The higher likelihood indicates that the second macro factor and the bilateral dynamics add information, but the out-of-sample forecasting performance continues to be low, in spite of a better in-sample fitting. Also, the mean Chen-Scott measurement 
errors decreased to sixty basis points. The unobservable factor $\theta_{2}$ can still be interpreted as the level, but $\theta_{1}$ is in some cases completely uncorrelated to the slope.

Table 4. Variance Decomposition. Fed 1D + Macro 2D + BR2D models.

\begin{tabular}{c|cccccccccccc} 
Imp & Resp & vix bmf3m & \multicolumn{2}{c}{ vix bmfsl } & \multicolumn{2}{c}{ vix bmf3y } & \multicolumn{2}{c}{ vix lbov } & \multicolumn{2}{c}{ vix lbov/ex } \\
\hline \hline \multirow{3}{*}{ FED } & & $\mathrm{h}=1$ & $\mathrm{~h}=9$ & $\mathrm{~h}=1$ & $\mathrm{~h}=9$ & $\mathrm{~h}=1$ & $\mathrm{~h}=9$ & $\mathrm{~h}=1$ & $\mathrm{~h}=9$ & $\mathrm{~h}=1$ & $\mathrm{~h}=9$ \\
& B3m & 01 & 02 & 00 & 02 & 01 & 03 & 01 & 02 & 01 & 03 \\
& B3y & 00 & 01 & 00 & 01 & 00 & 01 & 00 & 04 & 00 & 05 \\
VIX & B20y & 00 & 00 & 00 & 00 & 00 & 00 & 00 & 04 & 00 & 04 \\
& B3m & 04 & 26 & 02 & 20 & 04 & 32 & 02 & 21 & 02 & 21 \\
& B3y & 05 & 33 & 02 & 23 & 05 & 39 & 04 & 20 & 04 & 21 \\
& B20y & 20 & 48 & 27 & 38 & 20 & 53 & 34 & 15 & 36 & 16 \\
bmf/bov & B3m & 00 & 02 & 02 & 07 & 01 & 01 & 00 & 00 & 00 & 00 \\
& B3y & 00 & 02 & 03 & 10 & 00 & 01 & 00 & 03 & 00 & 01 \\
& B20y & 00 & 01 & 03 & 09 & 01 & 02 & 00 & 02 & 00 & 00 \\
& B3m & 19 & 12 & 38 & 22 & 17 & 09 & 68 & 51 & 68 & 50 \\
& B3y & 03 & 04 & 13 & 09 & 02 & 01 & 20 & 50 & 19 & 52 \\
$\theta_{2}$ & B20y & 00 & 01 & 02 & 04 & 00 & 01 & 05 & 69 & 05 & 70 \\
& B3m & 19 & 57 & 38 & 48 & 17 & 56 & 68 & 25 & 68 & 25 \\
& B3y & 91 & 61 & 81 & 57 & 93 & 58 & 76 & 23 & 76 & 21 \\
& B20y & 80 & 50 & 67 & 49 & 79 & 43 & 61 & 10 & 59 & 09
\end{tabular}

Table 4 show the variance decomposition of $\{1 \mathrm{~m}, 3 \mathrm{y}, 20 \mathrm{y}\}$-yields for forecast horizons of $\{1,9\}$ months ahead of our main models. In line with the preliminary models, the VIX is again the most important macro factor influencing the yields. Of the domestic yields, only the $3 y-1 \mathrm{~m}$ slope has some effect.

Next, Table 5 present the variance decomposition of the default probabilities. In the 9-month horizon decomposition (free from the initial condition effects) the results show that: 1) In all specifications, the FED has amost null effect on short bonds, but $73-93 \%$ of changes in implied default probabilities of bonds with long maturities are attributable to changes in the FED short rates. 2) The effect of the VIX is smaller on long bonds, but about $50 \%$ of changes in implied default probabilities of shorter bonds are attributable to changes in the VIX index. 3) Of the domestic factors, only the slope of the term structure has a relatively important effect, accounting for $11 \%$ of changes in implied probabilities of the short bond. 4) Thus, according to the model, the domestic short and long rate and the stock exchange index level Bovespa in local currency or in dollars are not sources of default probability movements.

Figure 3 shows the evolution of the 1-yearl survival probability along the sample, and Figure 4 the term structure of default probabilities in the last day of the sample. The figure indicates some robustness of the estimations.

Impulse response functions are plotted after the default probabilities. Each figure presents the effect of a shock of one standard deviation of a monthly variation in a state variable. Figure 5 evaluate the impact of a FED shock on itself, on the macro factors and on the $\{3 \mathrm{~m}, 3 \mathrm{y}, 20 \mathrm{y}\}$-yields. The next figure shows the response to one deviation of a monthly variation of VIX shocks. All the yield rates are increased about $1 \%$ in absolute terms 3 months after the shock an then decreases. Figure 7 shows the impact of the domestic macro factors. Changes in either the domestic short or long rate did not result in changes of the sovereign yields. But the domestic slope did cause an increase. It may indicate a change of expectations due to a future rise in inflation. A rise of the domestic stock exchange caused a small decrease of the yields.

Figure 8 shows the impact of an increase of one deviation of a monthly variation of the FED latent factor (approximately the FED short rate) on the default probabilities. It shows that the 
survival probability fall by up to $2 \%$ in relative terms. An increase in VIX also decreases the survival probability, but about $0.6 \%$ in relative terms. Of the domestic factors, only the BM\&F slope has some impact, decreasing the long end survival probability by about $0.35 \%$ in relative terms.

Table 5. Variance Decomposition of the Default Probabilities. Fed 1D + Macro 2D + BR 2D models.

\begin{tabular}{c|cccccccccccc} 
Imp & Resp & \multicolumn{2}{c}{ vix bmf3m } & \multicolumn{2}{c}{ vix bmfsl } & \multicolumn{2}{c}{ vix bmf3y } & \multicolumn{2}{c}{ vix lbov } & \multicolumn{2}{c}{ vix lbov/ex } \\
\hline \hline \multirow{3}{*}{ FED } & & $\mathrm{h}=1$ & $\mathrm{~h}=9$ & $\mathrm{~h}=1$ & $\mathrm{~h}=9$ & $\mathrm{~h}=1$ & $\mathrm{~h}=9$ & $\mathrm{~h}=1$ & $\mathrm{~h}=9$ & $\mathrm{~h}=1$ & $\mathrm{~h}=9$ \\
& B3m & 00 & 00 & 00 & 00 & 00 & 00 & 02 & 02 & 02 & 02 \\
& B3y & 08 & 29 & 07 & 21 & 09 & 29 & 10 & 42 & 21 & 59 \\
VIX & B20y & 51 & 79 & 47 & 73 & 52 & 78 & 66 & 88 & 80 & 93 \\
& B3m & 29 & 42 & 19 & 32 & 34 & 56 & 15 & 31 & 16 & 31 \\
& B3y & 36 & 33 & 31 & 31 & 55 & 51 & 29 & 25 & 26 & 18 \\
& B20y & 20 & 10 & 18 & 11 & 29 & 16 & 11 & 05 & 07 & 03 \\
bmf/bov bov & B3m & 01 & 03 & 08 & 11 & 01 & 01 & 00 & 00 & 00 & 00 \\
& B3y & 03 & 03 & 11 & 10 & 02 & 02 & 01 & 01 & 01 & 01 \\
& B20y & 01 & 01 & 06 & 03 & 01 & 01 & 00 & 00 & 00 & 00 \\
& B3m & 11 & 09 & 21 & 12 & 06 & 03 & 61 & 49 & 61 & 49 \\
& B3y & 09 & 07 & 11 & 06 & 01 & 00 & 45 & 24 & 38 & 16 \\
& B20y & 05 & 02 & 06 & 02 & 00 & 00 & 18 & 05 & 10 & 03 \\
& B3m & 11 & 46 & 21 & 44 & 06 & 39 & 61 & 18 & 61 & 18 \\
& B3y & 43 & 29 & 41 & 31 & 33 & 17 & 16 & 08 & 14 & 06 \\
& B20y & 23 & 08 & 24 & 11 & 18 & 05 & 06 & 02 & 03 & 01
\end{tabular}

\subsection{Default Probabilities}

Figure 3 depicts the path of 1 minus the probability of a default occurring before 1 year, that is, the market implied probability that the bond will survive for another year. It can be seen that different specifications tend to present similar probabilities. Figure 4 depicts the term structure of default survival probabilities for the last day of the sample.

\section{Conclusion}

This article proposed an approach combining term structure models with macro factors and reduced credit risk models, aiming to measure how unexpected macroeconomic changes affect sovereign default probabilities. Amato and Luisi (2005) also explore the same ideas with respect to corporate credit risk, but our article uses a fully interacting dynamics, in which macro factors affect and are affected by the credit spreads. Also, we presented and estimated an identified model, while other articles use super or sub-identified models.

We tested the influence of two domestic macro factors and term structure on the sovereign term structure of interest rates and of credit spreads, and the result was that VIX and FED had greater impact. We calculated variance decompositions and impulse response functions in order to make quantitative predictions. The model presented good fitting to data, but did not show good forecasting performance. Our results have shown that VIX is an important factor for the default probabilities of emerging market short-term bonds. On the other hand, the FED is an important indicator for the longer yields. 


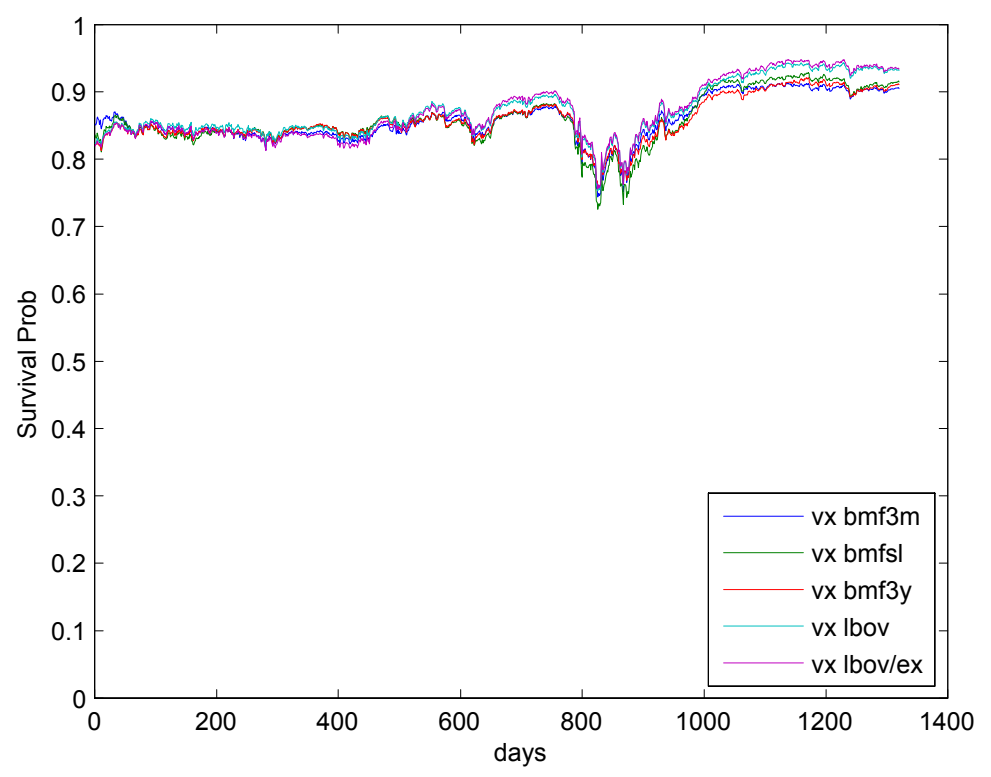

Figure 3:

\section{Bibliography}

Amato JD, Luisi M. Macro Factors in the Term Structure of Credit Spreads. Working paper 2006.

Ang A. Piazzesi, M., 2003. A no-arbitrage vector autoregression of term structure dynamics with macroeconomic and latent variables, Journal of Monetary Economics 50, 745-787.

Ang, A.; Dong, S. and M. Piazzesi, 2005. No-Arbitrage Taylor Rules. Working paper, University of Chicago.

Black, F. and J.C. Cox, 1976, Valuing corporate securities: Some effects of bond indenture provisions, Journal of Finance 31(2), 351-367.

Black, F. and M. Scholes, 1973, The pricing of options and corporate liabilities, Journal of Political Economy 81(3), 637-654.

Chen, R., Scott, L., 1993, Maximum Likelihood Estimation for a Multi-factor Equilibrium Model of the Term Structure of Interest Rates, Journal of Fixed Income, 3, 14-31.

Collin-Dufresne, P., Goldstein, R.S., and C.S. Jones, 2006. Identification of Maximal Affine Term Structure Models, Working paper.

Dai, Q. and K.J.Singleton, 2000, Specification analysis of affine term structure models, Journal of Finance 55, 1943-1978.

Dai, Q. and Philippon, Thomas, 2004, Government Deficits and Interest Rates: A No-Arbitrage Structural VAR Approach, Working paper.

Davidson, R. and J.G. MacKinnon , 1993, Estimation and Inference in Econometrics, Oxford University Press.

Diebold, Francis X., Monika Piazzesi, and Glenn D. Rudebusch, Modeling Bond Yields in Finance and Macroeconomics, American Economic Review, 2005, 95(2), pp. 415-20.

Duffie, D., 2001, Dynamic Asset Pricing Theory, $3^{\text {rd }}$ Ed., Princeton University Press.

Duffie, D. and R. Kan, 1996, A yield-factor model of interest rates, Mathematical Finance 6, 379- 


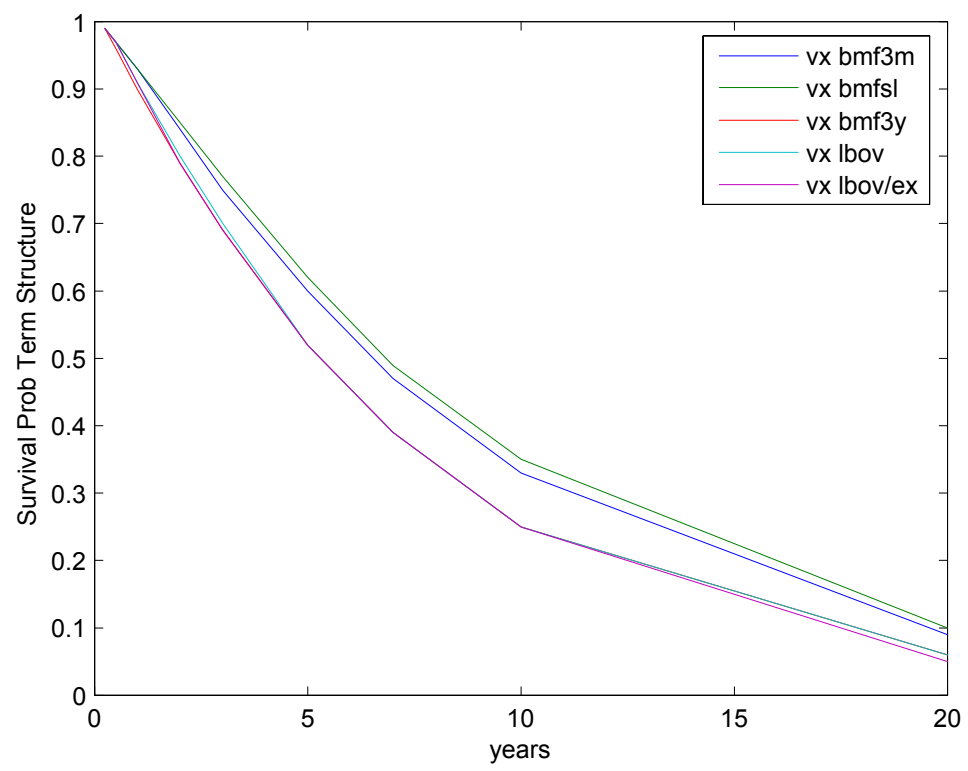

Figure 4:

406. Duffie, D., L. H. Pedersen, and K. J. Singleton, 2003, Modeling Sovereign Yield Spreads: A Case Study of Russian Debt, Journal of Finance 58, 119-159.

Duffie, D., and K.J. Singleton, 1999, Modeling term structures of defaultable bonds, Review of Financial Studies 12, 687-720.

Giesecke, K., 2004, Credit Risk Modeling and Valuation: An Introduction, Credit Risk Models and Management, Vol. 2, D. Shimko (Ed.), Riskbooks.

Ghezzi P, Xu D., 2002, From fundamentals to spreads. Deutsch Bank Global Markets Research.

Hordhal P, Tristani O, Vestin D. A joint econometric model of macroeconomic and term structure dynamics. Working paper 2003, European Central Bank.

Lando, D., 1998, On Cox processes and credit risky bonds, Review of Derivatives Research, 2(2/3), 99-120.

Leland, H.E., 1994, Risky debt, bond covenants and optimal capital structure, Journal of Finance, 49 (4), 1213-1252.

Leland, H.E. and K.B. Toft, 1996, Optimal capital structure, endogenous bankruptcy and the term structure of credit spreads, Journal of Finance, 50: 789-819.

Litterman, R. and J. Scheinkman, 1991, Common factors affecting bond returns, Journal of Fixed Income 1, 54-61.

Matsumura, M, Moreira, A, 2005. Can macroeconomic variables account for the term structure of sovereign spreads? Studying the Brazilian case. Texto Para Discussão 1106, IPEA.

Matsumura, M, Moreira, A, 2006. Macro factors and the Brazilian yield curve with no arbitrage models. Texto Para Discussão 1210, IPEA.

Merton, R.C., 1974, On the pricing of corporate debt: The risk structure of interest rates, Journal of Finance 29(2), 449-470.

Moreira, A.R. and K. Rocha, 2004, Two-Factor Structural Model of Determinants of Brazilian Sovereign Risk, Journal of Fixed Income, June 2004. 
Nelson, C.R. and A.F. Siegel, 1987, Parsimonious modeling of yield curves, Journal of Business 60(4), 473-489.

Pagès, H., 2001, Can liquidity risk be subsumed in credit risk? A case study from Brady bond prices, BIS Working Papers No 101.

Pearson, N.D. and T.-S. Sun, 1994, Exploiting the Conditional Density in Estimating the Term Structure: An Application to the Cox, Ingersoll, and Ross Model, Journal of Finance 49(4), 1279-1304.

Pericoli, M. and M. Taboga, 2006, Canonical term-structure models with observable factors and the dynamics of bond risk premiums, Temi di Discussioni, Banca D'Italia.

Rudebusch, G Wu T., 2004, A macro-finance model of the term structure, monetary policy and the economy, WP 2003-17, Federal Reserve Bank of San Francisco.

Schönbucher, P.J., 2003, Credit Derivatives Pricing Models, Wiley Finance.

\section{A Appendix}

\section{A.1 Identification}

In order to identify the unobservable factors $\theta$, we modify the method introduced by Dai and Singleton (2000) to the case with macro factors. There are several possibilities and only one choice is implemented. The identification is necessary because not all parameters can be estimated. There are linear transformations on the parameter space leaving the short rate, and thus the yields, constant. These transformations can be considered degrees of freedom that must be spent so that the model becomes identified. If a model is not identified, as Collin-Dufresne et al (2006) put it, two researchers using the same data can arrive at different sets of parameter estimates even if they succeed to maximize. Also, the impulse response functions could be arbitrarily changed and model forecasts would be meaningless. Let $\Psi=\left(\delta_{0}, \delta_{1}, K, \xi, \lambda_{0}, \lambda_{1}, \Sigma\right)$, the affine invariant transformation $T$ is defined on the space of the parameters by a nonsingular matrix $L$ such that $T_{L}(\Psi)=\left(\delta_{0},\left(L^{\top}\right)^{-1} \delta_{1}, L K L^{-1}, L \xi, \lambda_{0}, \lambda_{1}, L \Sigma\right)$. Another invariant transformation is the Brownian motion rotation $O$, which takes a vector of unobserved, independent Brownian motions into another vector of independent Brownian motions: $T_{O}(\Psi)=\left(\delta_{0}, \delta_{1}, K, \xi, O \lambda_{0}, O \lambda_{1}, \Sigma O^{\top}\right)$. The rotations do not affect the state factors and can always be used to make $\Sigma$ a triangular matrix. We impose a lower triangular $\Sigma$, which implies that macro factors do not react contemporaneously to monetary policy.

We impose $E(\theta)=0$ as Dai and Singleton (2000), and subtract the mean value of the macro factors, so that $E(M)=0$.Then, $\xi=0$. Also, in contrast to the case with purely latent factors, the transformations $L$ must preserve the macro factors, that is, $L=\left(\begin{array}{cc}I & 0 \\ A & B\end{array}\right)$. Here matrices $A$ and $B$ matrix are chosen such that $\operatorname{Var}(\theta)=\mathbb{I}, \sum_{M \theta}=0$, or

$$
L \Sigma=\left(\begin{array}{cc}
\Sigma_{M M} & 0 \\
0 & I
\end{array}\right)
$$

where, as said before, $\Sigma_{M M}$ is lower triangular. This implies that macro and monetary factors do not have correlated contemporaneous innovations.

There is another invariant transformation that must be used in case $L \Sigma$ has the special format shown above, $R=\left(\begin{array}{ll}I & 0 \\ 0 & O\end{array}\right)$, where $O$ is another rotation which makes $\Phi_{\theta \theta}$ lower triangular. Summing up, we have

$$
\Sigma=\left(\begin{array}{cc}
\Sigma_{M M} & 0 \\
0 & I
\end{array}\right), \quad \xi=0, \quad \Phi=\left(\begin{array}{cc}
\Phi_{M M} & \Phi_{M \theta} \\
\Phi_{\theta M} & \Phi_{\theta \theta}
\end{array}\right) \text { with } \Phi_{\theta \theta} \text { lower triangular. }
$$

This completes an exactly identified specification. 
We remark that another possibility is imposing a triangular $\Phi_{\theta \theta}^{\star}$ instead of $\Phi_{\theta \theta}$. Actually, many other identifications are possible.

Proof of the invariance of the likelihood with Chen-Scott under DS transformations. The likelihood is

$$
\begin{gathered}
\mathcal{L}(\Psi)=\sum_{t=2}^{T}\left(-\log |\operatorname{det} J|+\log f_{X}\left(M_{t}, \theta_{t} \mid M_{t-1}, \theta_{t-1}\right)\right) \\
=(T-1) \log |\operatorname{det} J|-\frac{1}{2}(T-1) \log \operatorname{det} \Sigma \Sigma^{\top} \\
-\frac{1}{2} \sum_{t=2}^{T}\left(X_{t}-\mu-\Phi X_{t-1}\right)^{\top}\left(\Sigma \Sigma^{\top}\right)^{-1}\left(X_{t}-\mu-\Phi X_{t-1}\right)
\end{gathered}
$$

where $J=\left(\begin{array}{cc}I & 0 \\ \beta^{M} & \beta^{\theta}\end{array}\right)$.

Will will show that $\mathcal{L}(\Psi)=\mathcal{L}\left(T_{L} \Psi\right)$, where $L$ is the invariant operator. The third term, when transformed, is unchanged:

$$
\begin{gathered}
\left(L X_{t}-L \mu-L \Phi L^{-1} L X_{t-1}\right)^{\top}\left(L \Sigma(\Sigma L)^{\top}\right)^{-1}\left(L X_{t}-L \mu-L \Phi L^{-1} L X_{t-1}\right) \\
=\left(L X_{t}-L \mu-L \Phi L^{-1} L X_{t-1}\right)^{\top}\left(L^{-1}\right)^{\top}\left(\Sigma \Sigma^{-1}\right) L^{-1}\left(L X_{t}-L \mu-L \Phi L^{-1} L X_{t-1}\right) \\
=\left(X_{t}-\mu-\Phi X_{t-1}\right)^{\top}\left(\Sigma \Sigma^{\top}\right)^{-1}\left(X_{t}-\mu-\Phi X_{t-1}\right)
\end{gathered}
$$

The first term, when transformed, results in

$$
\begin{gathered}
-\frac{1}{2}(T-1) \log \operatorname{det} L \Sigma(L \Sigma)^{\top}=-\frac{1}{2}(T-1)\left[\log \operatorname{det} \Sigma \Sigma^{\top}+\log \operatorname{det} L+\log \operatorname{det} L^{\top}\right] . \\
-\frac{1}{2}(T-1) \log \operatorname{det} \Sigma \Sigma^{\top}-(T-1) \log \operatorname{det} L
\end{gathered}
$$

Now, to calculate the transformed second term $-(T-1) \log |\operatorname{det} J|$, note that $\operatorname{det} J=\operatorname{det} B^{\theta}$, and that $\left(B L^{-1}\right)^{\theta}=\beta^{-1} B^{\theta}$ because $B L^{-1}=\left(\begin{array}{ll}B^{M} & B^{\theta}\end{array}\right)\left(\begin{array}{cc}I & 0 \\ -\beta^{-1} \alpha & \beta^{-1}\end{array}\right)$. So, the result of applying $L$ will be $-\log \left|\operatorname{det} \beta^{-1} B^{\theta}\right|=-\log \left|\operatorname{det} B^{\theta}\right|-\log \left|\operatorname{det} \beta^{-1}\right|=-\log \left|\operatorname{det} B^{\theta}\right|+\log |\operatorname{det} \beta|$. Now, since $\operatorname{det} L=\operatorname{det}\left(\begin{array}{cc}I & 0 \\ \alpha & \beta\end{array}\right)=\operatorname{det} \beta$, the $(T-1) \log \operatorname{det} L$ expression of the first two terms of the likelihood will cancel because of the different signs.

\section{A.2 Impulse Response Function and Variance Decomposition}

Impulse response functions and variance decompositions are used to analyze the impact of macro shocks on yields and default probabilities. The time impulse response function in discrete time is $X_{t}=\Sigma \varepsilon_{t}+\Phi \Sigma \varepsilon_{t-1}+\Phi^{2} \Sigma \varepsilon_{t-2}+\Phi^{3} \Sigma \varepsilon_{t-3}+\ldots$ Since $Y_{t}=A+B X_{t}$, the response of the yield curve to the shocks is

$$
\begin{array}{ccccc}
B \Sigma \varepsilon_{t} & B \Phi \Sigma \varepsilon_{t} & B \Phi^{2} \Sigma \varepsilon_{t} & B \Phi^{3} \Sigma \varepsilon_{t} & \ldots \\
t+0 & t+1 & t+2 & t+3 & \ldots
\end{array}
$$

In continuous time, we have $X_{t_{i} \mid t_{i-k}}=e^{-K\left(t_{i}-t_{i-k}\right)} X_{i-k}+\sum_{l=0}^{k-1} \int_{t_{i-k+l}}^{t_{i-k+l+1}} e^{-K\left(t_{i}-u\right)} \Sigma d w_{u}$. Using the approximation (3), it follows that the response of $X_{t}$ to a shock $\varepsilon_{t}$ in a interval of time of $d t$ is

$$
\begin{array}{ccccc}
\Sigma \sqrt{d t} \varepsilon_{t} & e^{-K d t} \Sigma \sqrt{d t} \varepsilon_{t} & e^{-2 K d t} \Sigma \sqrt{d t} \varepsilon_{t} & e^{-3 K d t} \Sigma \sqrt{d t} \varepsilon_{t} & \ldots \\
t+0 & t+1 & t+2 & t+3 & \ldots
\end{array}
$$


The response of the yield $Y_{t}$ is

$$
\begin{array}{ccccc}
B \Sigma \sqrt{d t} \varepsilon_{t} & B e^{-K d t} \Sigma \sqrt{d t} \varepsilon_{t} & B e^{-2 K d t} \Sigma \sqrt{d t} \varepsilon_{t} & B e^{-3 K d t} \Sigma \sqrt{d t} \varepsilon_{t} & \ldots \\
t+0 & t+1 & t+2 & t+3 & \ldots
\end{array}
$$

and the response of the $\log$ of the survival probability $\log \operatorname{Pr}(t, \tau)$ is

$$
\begin{array}{ccccc}
\beta^{\operatorname{Pr}} \Sigma \sqrt{d t} \varepsilon_{t} & \beta^{\operatorname{Pr}} e^{-K d t} \Sigma \sqrt{d t} \varepsilon_{t} & \beta^{\operatorname{Pr}} e^{-2 K d t} \Sigma \sqrt{d t} \varepsilon_{t} & \beta^{\operatorname{Pr}} e^{-3 K d t} \Sigma \sqrt{d t} \varepsilon_{t} & \ldots \\
t+0 & t+1 & t+2 & t+3 & \ldots
\end{array} .
$$

In discrete time, the Mean Squared Error of the s-periods ahead error $X_{t+s}-E X_{t+s \mid t}$ is $M S E=$ $\Sigma \Sigma^{\top}+\Phi \Sigma \Sigma^{\top} \Phi^{\top}+\Phi^{2} \Sigma \Sigma^{\top}\left(\Phi^{2}\right)^{\top}+\ldots+\Phi^{s} \Sigma \Sigma^{\top}\left(\Phi^{s}\right)^{\top}$. The contribution of the j-th factor to the MSE of $X_{t+s}$ will be then $\Sigma_{j} \Sigma_{j}^{\top}+\Phi \Sigma_{j} \Sigma_{j}^{\top} \Phi^{\top}+\Phi^{2} \Sigma_{j} \Sigma_{j}^{\top}\left(\Phi^{2}\right)^{\top}+\ldots+\Phi^{s} \Sigma_{j} \Sigma_{j}^{\top}\left(\Phi^{s}\right)^{\top}$, while the j-th factor contribution to the $M S E$ of $Y_{t+s}$ is $B \Sigma_{j} \Sigma_{j}^{T} B^{\top}+B \Phi \Sigma_{j} \Sigma_{j}^{\top} \Phi^{\top} B^{\top}+B \Phi^{2} \Sigma_{j} \Sigma_{j}^{\top}\left(\Phi^{2}\right)^{\top} B^{\top}+\ldots+B \Phi^{s} \Sigma_{j} \Sigma_{j}^{\top}\left(\Phi^{s}\right)^{\top} B^{\top}$.

In continuous time, it turns out that the s-period ahead $M S E$ of is the integral: $M S E=$ $\int_{t}^{t+s} e^{-K(t+s-u)} \Sigma \Sigma^{\top}\left(e^{-K(t+s-u)}\right)^{\top} d t$. Hence, the contribution corresponding to the $\mathrm{j}$-th factor in the variance decomposition of $X_{t+s}, Y_{t+s}$ and $\log \operatorname{Pr}(t, \tau)$ at time $t$ are

$$
\begin{gathered}
\int_{t}^{t+s} e^{-K(t+s-u)} \Sigma_{j} \Sigma_{j}^{\top}\left(e^{-K(t+s-u)}\right)^{\top} d t \\
B^{\top}\left(\int_{t}^{t+s} e^{-K(t+s-u)} \Sigma_{j} \Sigma_{j}^{\top}\left(e^{-K(t+s-u)}\right)^{\top} d t\right) B \\
\left(\beta^{\operatorname{Pr}}\right)^{\top}\left(\int_{t}^{t+s} e^{-K(t+s-u)} \Sigma_{j} \Sigma_{j}^{\top}\left(e^{-K(t+s-u)}\right)^{\top} d t\right) \beta^{\operatorname{Pr}} .
\end{gathered}
$$
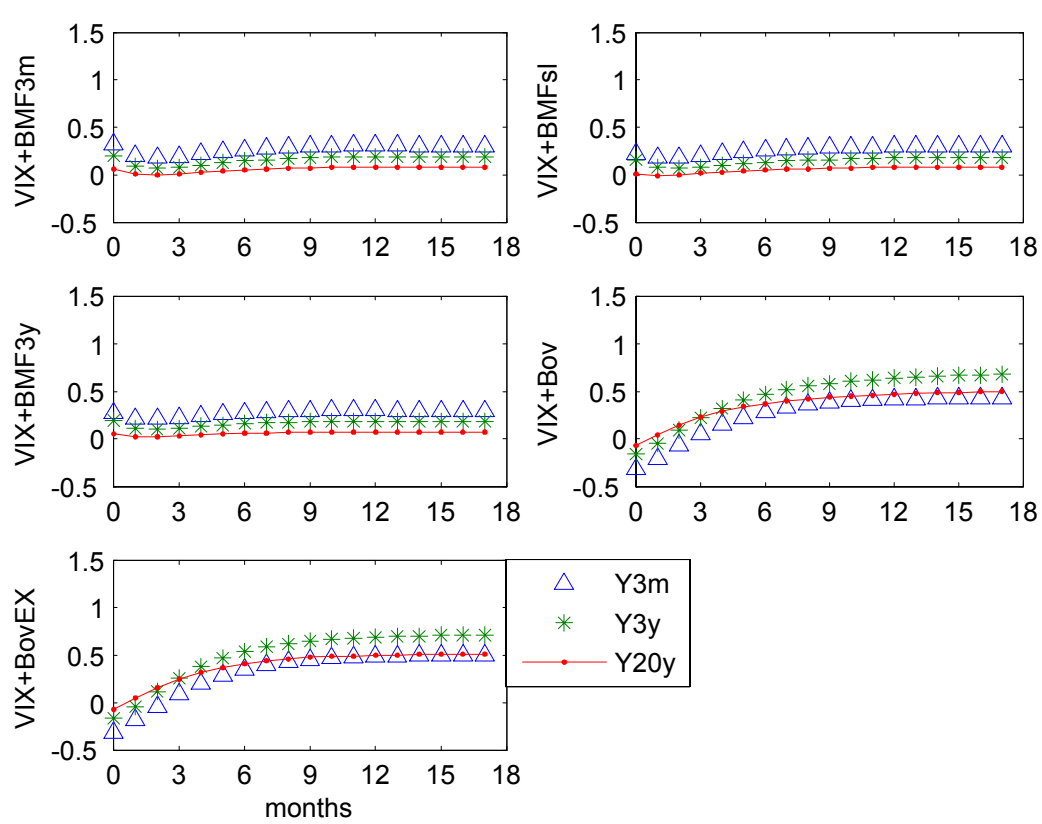

Figure 5: Response of yields to FED shocks. 

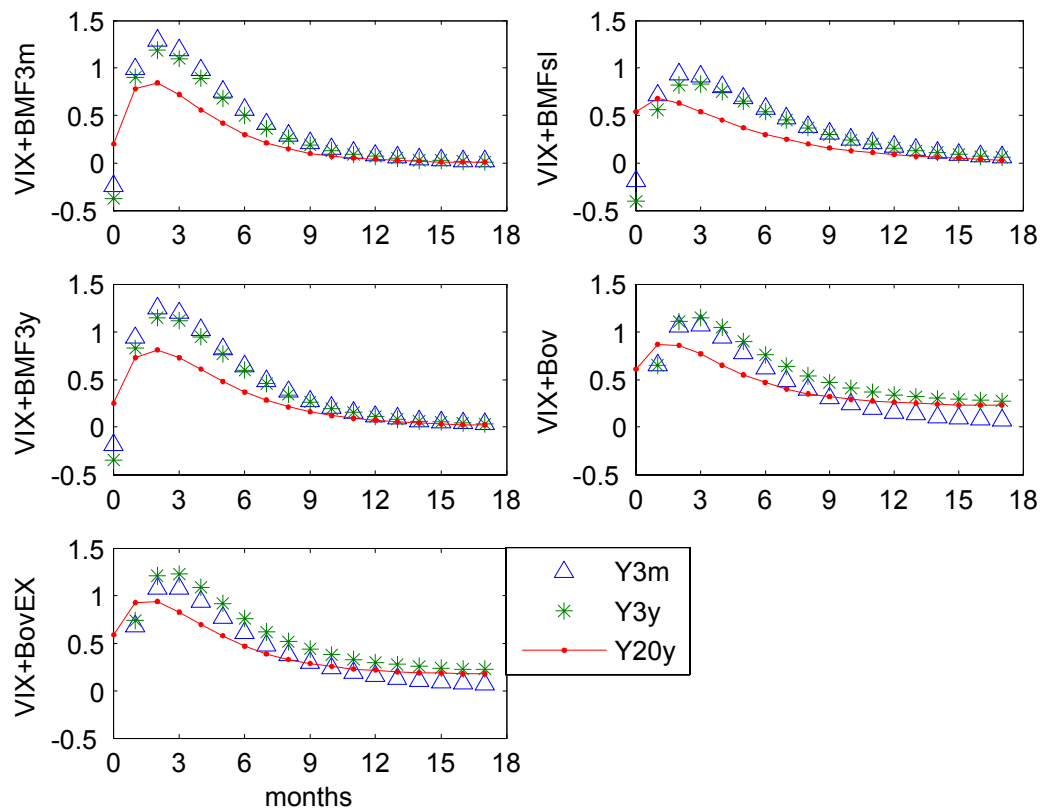

Figure 6: Response of yields to VIX shocks.
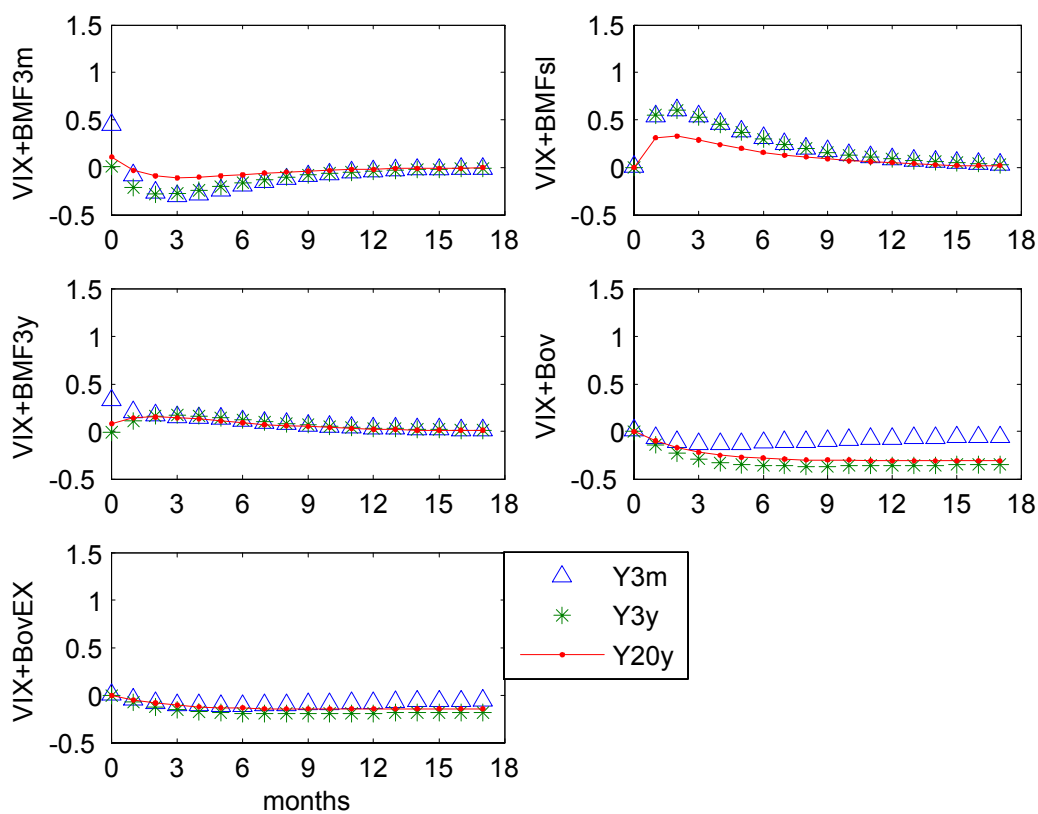

Figure 7: Response of yields to BM\&F or Bovespa shocks. 


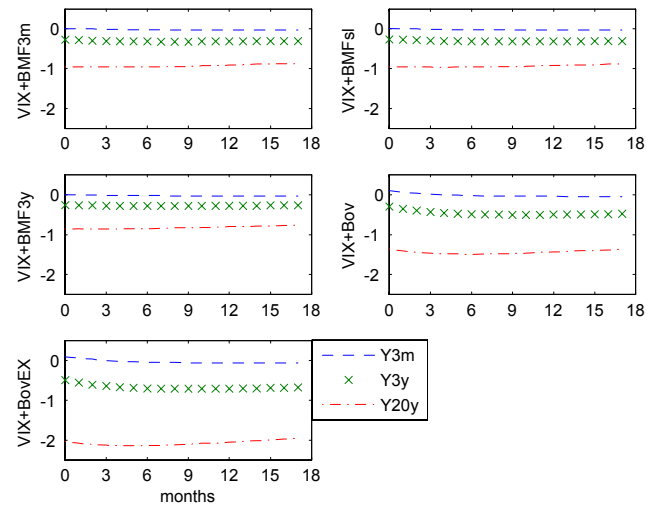

Figure 8: IR Survival Probabilities: FED shock.
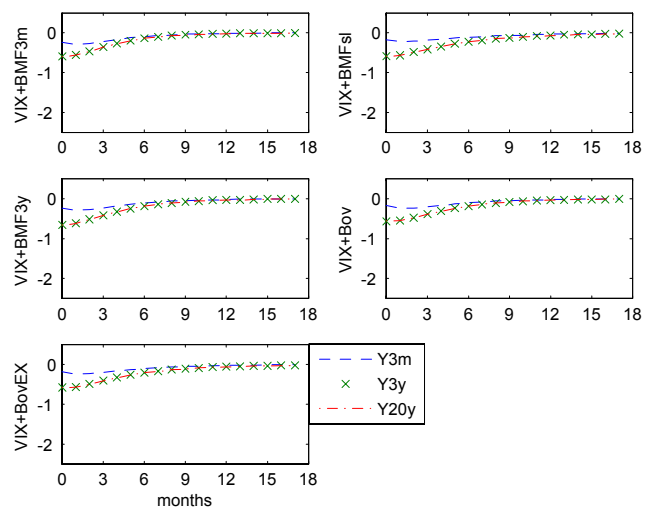

Figure 9: IR Survival Probabilities: VIX shock.
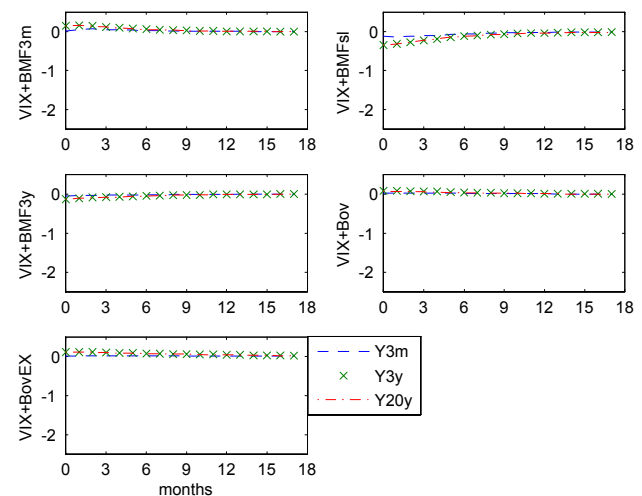

Figure 10: IR Survival Probabilities: BM\&F or Bovespa shocks. 